\title{
Effect of Broccoli Powder on Consumer Perception and Sensory Characteristics of Cookies
}

\author{
Jun Ho Lee ${ }^{\dagger}$ and Hye Young Lee \\ Department of Food Science and Engineering, Daegu University, Gyeongbuk 712-714, Korea
}

\begin{abstract}
The effects of baking with broccoli powder on the consumer perception and sensory characteristics were investigated using a model system of cookies incorporated with broccoli powder as a value-added food ingredient. Broccoli powder was incorporated into cookie dough at 5 levels $(0 \%, 1 \%, 2 \%, 3 \%$, and $4 \%$, w/w) by replacing equivalent amount of wheat flour of the cookie dough. After aging and sheeting, cookies were baked at $170^{\circ} \mathrm{C}$ for $8 \mathrm{~min}$ in an oven. The baked cookies were cooled to room temperature for 1 hour and packed in airtight bags prior to all measurements. Control received the most favorable mean score, which was not significantly different from samples with $1 \%$ broccoli powder for color preference $(p>0.05)$. Results of the consumer preference on taste showed a similar trend. Consumers did not find any significant differences on aftertaste and flavor among samples prepared by replacing wheat flour with up to $2 \%$ broccoli powder $(p>0.05)$. Overall, incorporation of $1 \%$ broccoli powder in the formulation would result in the most favorable broccoli cookies for the consumers without sacrificing the sensory qualities, while still taking advantages of health benefits of broccoli. Correlation analysis indicated that broccoli powder concentration was significantly negatively correlated with the consumer preference for color, taste, aftertaste, flavor, overall acceptability and positively correlated with sensory color, taste, and flavor $(\mathbf{p}<\mathbf{0 . 0 5})$. Consumens' color, taste, aftertaste, and flavor were well comelated with the overall acceptability $(\mathbf{p}<\mathbf{0 . 0 5})$. Sensory intensity results are also presented.
\end{abstract}

Key words: consumer perception, sensory, cookies, broccoli powder, correlation

\section{INTRODUCTION}

Broccoli is one of the major agricultural products commonly consumed around the world. Broccoli belongs to Brassica family and is a rich source of health-promoting phytochemicals, including glucosinolates, flavonoids, vitamins, and minerals (1-4). Many studies have indicated its health benefit effects; for example, the consumption of broccoli is inversely related with the occurrence of cancer in human (5). Broccoli is also a significant source of quercetin (6), phenolics, ascorbic acid, carotenoids (7), calcium, folic acid, and fiber content (8). In addition, intake of cruciferous vegetables such as broccoli significantly reduced the risk of a number of cancers, even with as little as $10 \mathrm{~g} /$ day $(9,10)$.

As modern food processing is aimed at manufacturing safe, convenient, and health-promoting food products, much attention is given to develop healthy functional food products. Among them, cookies have been one of the most favored baking products whose properties can be easily improved by incorporating various kinds of food ingredients. Many studies have been reported so far for the quality of cookies prepared with various func- tional food ingredients (11-18).

Identification of ways to incorporate broccoli as a health food ingredient in human diet and use of the vegetable as a value-added food component could provide many health benefits. Despite previous investigations, information on the potential for incorporation of broccoli powder in bakery products such as cookies and its contribution to sensory characteristics and consumer acceptance of the final product are scant. Therefore, the objectives of this research were to evaluate the impact of baking on sensory properties and consumer preference for cookies incorporated with different levels of broccoli powders. The data generated by this experiment will provide consumer experimental data to help develop new types of value-added or functional foods.

\section{MATERIALS AND METHODS}

\section{Preparation of raw materials}

Fresh broccoli, harvested in April 2008, was obtained from Chungtaesan Farm located in Hoengseong-gun, Gangwon-do, Korea. The soft wheat flour (ranked 1st; CJ Corp., Seoul, Korea), granulated sugar (CJ Corp., 
Incheon, Korea), butter (Seoul Milk Coop., Yongin, Gyeonggi-do, Korea), baking powder (Yuchung Foods Co., Ltd., Daegu, Korea), roasted salt (Bora Food Co., Ltd., Naju, Jeonnam, Korea), powdered skim milk (Seoul Dairy Co-op, Yangju, Gyeonggi-do, Korea), and eggs were procured from a local market and stored at room temperature before use. One hundred grams of the soft wheat flour contained $77 \mathrm{~g}$ of carbohydrates, $5 \mathrm{~g}$ of protein, $1.5 \mathrm{~g}$ of lipids, and $10 \mathrm{mg}$ of sodium.

Prewashed broccoli was steam blanched for $5 \mathrm{~min}$ at $100^{\circ} \mathrm{C}$ after removal of the stems. Surface moisture of the sample was removed by cooling at room temperature for $1 \mathrm{hr}$, then the sample was lyophilized using a freeze dryer (FDU-1100, Tokyo Rikakikai Co., Tokyo, Japan) at a vacuum pressure of $8.5 \mathrm{~Pa}$ after being frozen at $-80^{\circ} \mathrm{C}$ for $24 \mathrm{hr}$ in a deep freezer (VLT 1450-3-D-14, Thermo Electron Corp., Asheville, NC, USA). Dehydrated broccoli was milled using an analytical mill (DA282, Daesung Artlon Co., Ltd., Paju, Gyeonggi-do, Korea) at maximum speed for $90 \mathrm{sec}$ and sieved to yield particle sizes less than $150 \mu \mathrm{m}$. Broccoli powders were then placed in a desiccator containing silica gel prior to cookie making, all of which took within one day.

\section{Dough preparation and baking}

Ingredients were mixed in a Kitchen Aid mixer (model 5K5SS, Whirlpool Corp., St. Joseph, MI, USA) using a flat beater attachment as described in AACC method 10-52 (19) by substituting up to 4\% (wt.) of broccoli powder based on the total weight of the soft wheat flour and broccoli powder mixture given in Table 1. The dough was aged for $2 \mathrm{hr}$ in a $4^{\circ} \mathrm{C}$ refrigerator and then sheeted to a thickness of $0.4 \mathrm{~cm}$ using a rolling pin. The cookies were cut with a cookie cutter to a $4 \mathrm{~cm}$ diameter and transferred to a lightly greased baking tray. The cookies were baked at $170^{\circ} \mathrm{C}$ for $4 \mathrm{~min}$, then the tray was rotated and baked for another $4 \mathrm{~min}$ in a multi-functional convection oven (model GOR-704C, TongYang Magic Corp., Seoul, Korea). The baked cookies were cooled to room temperature for $1 \mathrm{hr}$ and packed

Table 1. Formulation of cookies on substitution of broccoli powder for soft wheat flour

\begin{tabular}{lrrrrr}
\hline \multirow{2}{*}{ Ingredients $(\mathrm{g})$} & \multicolumn{5}{c}{ Sample } \\
\cline { 2 - 6 } & $0 \%$ & $1 \%$ & $2 \%$ & $3 \%$ & $4 \%$ \\
\hline Soft wheat flour & 300 & 297 & 294 & 291 & 288 \\
Broccoli powder & 0 & 3 & 6 & 9 & 12 \\
Granulated sugar & 150 & 150 & 150 & 150 & 150 \\
Butter & 135 & 135 & 135 & 135 & 135 \\
Baking powder & 1.5 & 1.5 & 1.5 & 1.5 & 1.5 \\
Salt & 1.5 & 1.5 & 1.5 & 1.5 & 1.5 \\
Egg & 75 & 75 & 75 & 75 & 75 \\
\hline Total & 663 & 663 & 663 & 663 & 663 \\
\hline
\end{tabular}

in airtight bags.

\section{Consumer testing}

The consumer test, an acceptance test, was conducted on 50 adults ( 25 females, 25 males aged between 20 and 29 years old). The subjects were informed that the cookies were made by adding various amount of broccoli powder. All samples were labeled with randomly-generated three-digit numbers and five samples were presented in random order. Participants were asked to smell before tasting each sample of cookie. After evaluating each sample, participants judged color, flavor, taste, chewiness, aftertaste, and overall acceptability using a structured numeric scale of nine points (9-point hedonic scale), wherein $9=$ like extremely, $8=$ like very much, $7=$ like moderately, $6=$ like slightly, $5=$ neither like nor dislike, $4=$ dislike slightly, $3=$ dislike moderately, $2=$ dislike very much, and $1=$ dislike extremely. Consumers received a tray containing the samples, a glass of water, and an evaluation sheet. Participants were asked to rinse their palates between samples and break for 30 seconds. Enough space was given to handle the samples and the questionnaire, and the evaluation time was not constrained.

\section{Sensory analysis}

A panel of 10 assessors ( 6 females, 4 males aged between 20 and 26 years old) were selected from the students in the Department of Food Science and Engineering at Daegu University (Gyeongbuk, Korea). The assessors were screened by conducting 10 sets of triangle tests discriminating taste between samples containing 2 or $4 \%$ broccoli powder under red fluorescent light. Those who correctly answered more than $60 \%$ of the tests were passed as potential panelist for further training. On each day, assessors received a total of five samples and a 2 min interval was allowed between each sample to reduce the likelihood of carryover. Each assessor was provided with water and asked to cleanse their palate between testings. Sample attributes were scored on 7-point category scales, wherein $7=$ extremely strong, $6=$ moderately strong, 5=slightly strong, 4=neither strong nor weak, $3=$ slightly weak, $2=$ moderately weak, and $1=$ extremely weak. Flavor and hardness were evaluated under red fluorescent light while color was done under regular fluorescent light.

\section{Statistical analysis}

The statistical analysis was done using the SAS Statistical Analysis System for Windows v9.1 (SAS Inst. Inc., Cary, NC, USA). The means were compared with Duncan's multiple range test at $5 \%$ level of significance and Pearson correlation coefficients were also determined. 
Table 2. Mean scores of consumer acceptance results (9-point hedonic scale) for cookies incorporated with different levels of broccoli powder

\begin{tabular}{lcccccc}
\hline \multirow{2}{*}{ Sample } & \multicolumn{5}{c}{ Consumer } & attributes \\
\cline { 2 - 6 } & Color & Taste & Aftertaste & Flavor & Chewiness & Overall acceptability \\
\hline 0 \% (Control) & $7.42^{\mathrm{a}}$ & $6.90^{\mathrm{a}}$ & $6.12^{\mathrm{a}}$ & $6.46^{\mathrm{a}}$ & $5.76^{\mathrm{a}}$ & $6.62^{\mathrm{a}}$ \\
$1 \%$ sample & $6.78^{\mathrm{a}}$ & $6.48^{\mathrm{ab}}$ & $6.48^{\mathrm{a}}$ & $5.90^{\mathrm{a}}$ & $5.92^{\mathrm{a}}$ & $6.08^{\mathrm{a}}$ \\
$2 \%$ sample & $5.66^{\mathrm{b}}$ & $5.76^{\mathrm{b}}$ & $5.62^{\mathrm{a}}$ & $5.80^{\mathrm{a}}$ & $5.60^{\mathrm{a}}$ & $5.82^{\mathrm{a}}$ \\
$3 \%$ sample & $4.62^{\mathrm{c}}$ & $4.82^{\mathrm{c}}$ & $4.74^{\mathrm{b}}$ & $4.94^{\mathrm{b}}$ & $5.20^{\mathrm{a}}$ & $4.54^{\mathrm{b}}$ \\
$4 \%$ sample & $3.78^{\mathrm{d}}$ & $4.50^{\mathrm{c}}$ & $4.36^{\mathrm{b}}$ & $4.38^{\mathrm{b}}$ & $5.54^{\mathrm{a}}$ & $4.16^{\mathrm{b}}$ \\
\hline
\end{tabular}

${ }^{\mathrm{a}-\mathrm{d}}$ Different letters within the same column indicate significant difference $(\mathrm{p}<0.05)$.

\section{RESULTS AND DISCUSSION}

A 9-point hedonic scale was used to determine which cookies incorporated with different levels of broccoli powder were preferred by the majority of consumers. Table 2 shows the mean scores of consumer acceptance results for the several attributes including color, taste, aftertaste, flavor, chewiness, and overall acceptability whilst Fig. 1 presents the spider charts on each attribute, respectively. In terms of color, the control and $1 \%$ sample received the comparatively favorable mean scores of 7.42 and 6.78, respectively, with no significant difference $(p>0.05)$, followed by $2 \%$ sample. On the other hand, $4 \%$ sample received the lowest mean score of 3.78 with respect to color among all samples tested $(\mathrm{p}<0.05)$. In fact, color acceptance decreased as the percent of broccoli incorporation increased in the formulation. Similar results were reported for cookies containing various levels of aged garlic where color preference decreased as the aged garlic content increased from 0 to $7 \%(18)$.

The consumer preferences on taste and aftertaste were also significantly affected by the amount of broccoli powder incorporated in the sample $(p<0.05)$. The scores of taste and aftertaste acceptability varied from 4.50 to

Taste

Color

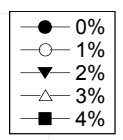

$-4 \%$
Overall acceptability
Flavor

\section{Chewiness}

Fig. 1. Consumer acceptance profiles of cookies incorporated with different levels of broccoli powder.
6.90 and 4.36 to 6.12 , respectively. It is noted that the control and $1 \%$ sample received significantly higher scores of taste and aftertaste acceptability $(\mathrm{p}<0.05)$.

The mean scores of flavor acceptability ranged from 4.38 to 6.46 . The control and samples with $1 \%$ and $2 \%$ broccoli powder received significantly higher mean scores than those of $3 \%$ and $4 \%$ samples $(p<0.05)$. There were no significant differences found among control, $1 \%$, and $2 \%$ samples nor between $3 \%$ and $4 \%$ samples in terms of consumer flavor acceptability $(\mathrm{p}>0.05)$. Thus, the consumers appeared to accept the broccoli flavor in the cookies unless it became too strong. Similar findings were reported for Gochujang made with strawberry puree (20), tofu made with Yakong (21), and Baikseolgi made with strawberry powders (22).

The consumer preference of chewiness was not significantly affected by the amount of broccoli powder incorporated in the sample $(p>0.05)$. The scores of chewiness acceptability varied from 5.20 to 5.92 , and were not significantly different from each other $(\mathrm{p}>0.05)$. This also indicates that all samples were considered to be somewhere between "neither like nor dislike" and "like slightly". Notwithstanding, it is noted that cookies with $1 \%$ broccoli powder received the highest score for chewiness acceptability. Seog et al. (23) also reported no significant differences in chewiness acceptability among tofu samples containing up to $3 \%$ of water dropwort juice. In addition, the broccoli powder incorporation in the cookie formulation did not appear to be a strong factor for the consumer preference on chewiness.

With respect to overall acceptability, control samples received the highest mean score of 6.62 ; however, that is not significantly different from that of $1 \%$ and $2 \%$ samples $(p>0.05)$. Four percent $(4 \%)$ samples received the lowest mean score of 4.16 , a significantly lower score than those of others except for $3 \%$ sample $(p<0.05)$. It is noted that incorporation of broccoli powder up to $2 \%$ in the formulation of cookies did not significantly influence the consumers' acceptability in all attributes tested except for color. Therefore, incorporation of $1 \%$ broccoli powder in the formulation of cookies would be recom- 
Table 3. Mean scores of sensory intensity results (9-point intensity scale) for cookies incorporated with different levels of broccoli powder

\begin{tabular}{|c|c|c|c|c|}
\hline \multirow{2}{*}{ Sample } & \multicolumn{4}{|c|}{ Sensory attributes } \\
\hline & Color & Taste & Flavor & Hardness \\
\hline $0 \%$ (Control) & $1.5^{\mathrm{d}}$ & $1.3^{\mathrm{e}}$ & $1.7^{\mathrm{c}}$ & $4.8^{\mathrm{a}}$ \\
\hline $1 \%$ sample & $2.7^{\mathrm{c}}$ & $3.3^{\mathrm{d}}$ & $2.4^{\mathrm{c}}$ & $4.2^{\mathrm{a}}$ \\
\hline $2 \%$ sample & $4.6^{\mathrm{b}}$ & $4.0^{\mathrm{c}}$ & $4.3^{\mathrm{b}}$ & $4.9^{\mathrm{a}}$ \\
\hline $3 \%$ sample & $4.7^{\mathrm{b}}$ & $4.9^{\mathrm{b}}$ & $3.9^{\mathrm{b}}$ & $4.2^{\mathrm{a}}$ \\
\hline $4 \%$ sample & $5.8^{\mathrm{a}}$ & $5.9^{\mathrm{a}}$ & $5.3^{\mathrm{a}}$ & $3.8^{\mathrm{a}}$ \\
\hline
\end{tabular}

${ }^{\mathrm{a}-\mathrm{e}}$ Different letters within the same column indicate significant difference $(\mathrm{p}<0.05)$.

mended to take advantage of health benefits of broccoli without sacrificing the color acceptance by the consumers.

The results of the sensory analysis are presented in Table 3. Intensity scores for cookies showed that sensory color, taste, and flavor attributes were significantly affected by different levels of broccoli powder incorporated in the formulation of cookies. Increases in broccoli powder concentration up to $4 \%$ in the cookie formulation significantly increased the intensities of sensory color, taste, and flavor attributes $(p<0.05)$. It is interesting to note that sensory hardness was not affected by broccoli powder concentration $(\mathrm{p}>0.05)$ although the physical measurements indicated otherwise (24). Lee and Oh (25) also reported that significant differences were found in mechanical hardness $(\mathrm{p}<0.05)$ but not in sensory hardness ( $p>0.05$ ) among cookie samples with $0 \sim 30 \%$ brown rice flour.

The correlation among all consumer attributes and sensory attributes for cookies incorporated with different levels of broccoli powder is given in Table 4. Consumers' overall acceptability attribute had a significant negative correlation to broccoli concentration and significant positive correlations to all the consumer attributes including color, taste, aftertaste, and flavor $(\mathrm{p}<0.05)$. Color, taste, aftertaste, and flavor consumer attributes negatively correlated with broccoli concentration $(p<0.05)$ whilst chewiness had no correlation to any of the attributes measured $(p>0.05)$. All sensory attributes, except for hardness, had significant positive correlations to broccoli concentration $(p<0.05)$. Finally, the hardness sensory attribute also had no correlation to any of the attributes measured.

\section{REFERENCES}

1. Cao G, Sofic E, Prior RL. 1996. Antioxidant capacity of tea and common vegetables. J Agric Food Chem 44: 34263431.

2. Plumb GW, Lambert N, Chambers SJ, Wanigatunga S, Heaney RK, Plumb JA. 1996. Are whole extracts and purified glucosinolates from cruciferous vegetables antioxidants? Free Radical Res 25: 75-86.

3. Bahorun T, Luximon-Ramma A, Crozier A, Aruoma OI. 2004. Total phenol, flavonoids, proanthocyanidin and vitamin C levels and antioxidant activities of Mauritian vegetables. J Sci Food Agric 84: 1553-1561.

4. Chun OK, Kim DO, Smith N, Schroeder D, Han JT, Lee CY. 2005. Daily consumption of phenolics and total antioxidant capacity from fruit and vegetables in the American diet. J Sci Food Agric 85: 1715-1724.

5. Roy MK, Juneja LR, Isobe S, Tsushida T. 2009. Steam processed broccoli (Brassica oleracea) has higher antioxidant activity in chemical and cellular assay systems. Food Chem 114: 263-269.

6. Nielsen SE, Kall M, Justesen U, Schou A, Dragsted LO. 1997. Human absorption and excretion of flavonoids after broccoli consumption. Cancer Lett 114: 173-174.

7. Zhang D, Hamauzu Y. 2004. Phenolics, ascorbic acid, carotenoids and antioxidant activity of broccoli and their changes during conventional and microwave cooking. Food Chem 88: 503-509.

8. Kaur C, Kumar K, Anil D, Kapoor HC. 2007. Variations in antioxidant activity in broccoli (Brassica oleracea L.) cultivars. J Food Biochem 31: 621-638.

9. Kohlmeier L, Su L. 1997. Cruciferous vegetable consumption and colorectal cancer risk: meta-analysis of the

Table 4. Correlation between all consumer attributes and sensory attributes for cookies incorporated with different levels of broccoli powder

\begin{tabular}{|c|c|c|c|c|c|c|c|c|c|c|}
\hline & & \multirow[b]{2}{*}{$\begin{array}{c}\text { Broccoli } \\
\text { concentration }\end{array}$} & \multicolumn{5}{|c|}{ Consumer attributes } & \multicolumn{3}{|c|}{ Sensory attributes } \\
\hline & & & Color & Taste & Aftertaste & Flavor & $\begin{array}{c}\text { Overall } \\
\text { acceptability }\end{array}$ & Color & Taste & Flavor \\
\hline $\begin{array}{l}\text { Consumer } \\
\text { attributes }\end{array}$ & $\begin{array}{l}\text { Color } \\
\text { Taste } \\
\text { Aftertaste } \\
\text { Flavor } \\
\text { Chewiness } \\
\text { Overall } \\
\quad \text { acceptability }\end{array}$ & $\begin{array}{l}-0.997^{* * *} \\
-0.989^{* *} \\
-0.926^{*} \\
-0.978^{* *} \\
-0.679^{\mathrm{NS}} \\
-0.974^{* *}\end{array}$ & $\begin{array}{l}0.995^{* * *} \\
0.952^{*} \\
0.974^{* *} \\
0.723^{\mathrm{NS}} \\
0.977^{* *}\end{array}$ & $\begin{array}{l}0.957^{*} \\
0.971^{* *} \\
0.776^{\mathrm{NS}} \\
0.985^{* *}\end{array}$ & $\begin{array}{l}0.916^{*} \\
0.810^{\mathrm{NS}} \\
0.942^{*}\end{array}$ & $\begin{array}{l}0.641^{\mathrm{NS}} \\
0.992^{* * *}\end{array}$ & & & & \\
\hline $\begin{array}{l}\text { Sensory } \\
\text { attributes }\end{array}$ & $\begin{array}{l}\text { Color } \\
\text { Taste } \\
\text { Flavor } \\
\text { Hardness }\end{array}$ & $\begin{array}{c}0.970^{* *} \\
0.981^{* *} \\
0.944^{*} \\
-0.687^{\mathrm{NS}}\end{array}$ & $\begin{array}{l}-0.964^{* *} \\
-0.964^{* *} \\
-0.940^{*} \\
0.658^{\mathrm{NS}}\end{array}$ & $\begin{array}{l}-0.947^{*} \\
-0.954^{*} \\
-0.911^{*} \\
0.657^{\mathrm{NS}}\end{array}$ & $\begin{array}{c}-0.864^{\mathrm{NS}} \\
-0.836^{\mathrm{NS}} \\
-0.850^{\mathrm{NS}} \\
0.571^{\mathrm{NS}}\end{array}$ & $\begin{array}{l}-0.901^{*} \\
-0.955^{*} \\
-0.864^{\mathrm{NS}} \\
0.812^{\mathrm{NS}}\end{array}$ & $\begin{array}{l}-0.896^{*} \\
-0.942^{*} \\
-0.850^{\mathrm{NS}} \\
0.768^{\mathrm{NS}}\end{array}$ & $\begin{array}{c}0.966^{* *} \\
0.988^{* *} \\
-0.526^{\mathrm{NS}}\end{array}$ & $\begin{array}{c}0.929^{*} \\
-0.708^{\mathrm{NS}}\end{array}$ & $-0.469^{\mathrm{NS}}$ \\
\hline
\end{tabular}

${ }^{\mathrm{NS}}$ Not significant. Significant at ${ }^{*} \mathrm{p}<0.05,{ }^{* *} \mathrm{p}<0.01,{ }^{* * *} \mathrm{p}<0.001$. 
epidemiological evidence. FASEB $J$ 11: A369.

10. Price KR, Casuscelli F, Colquhoun IJ, Rhodes MJC. 1998. Composition and content of flavonol glycosides in broccoli florets (Brassica oleracea) and their fate during cooking. J Sci Food Agric 77: 468-472.

11. Han JS, Kim JA, Han GP, Kim DS. 2004. Quality characteristics of functional cookies with added potato peel. Korean J Food Cookery Sci 20: 63-69.

12. Lee JH, Kim GH, Kim YS. 2005. Physicochemical and sensory properties of dough and cookie added with black rice flour. Food Eng Prog 9: 26-31.

13. Lee JY, Ju JC, Park HJ, Heu ES, Choi SY, Shin JH. 2006. Quality characteristics of cookies with bamboo leaves powder. Korean J Food Nutr 19: 1-7.

14. Uysal H, Bilgiçli N, Elgün A, İbanoğlu S, Herken EN, Demir MK. 2007. Effect of dietary fibre and xylanase enzyme addition on the selected properties of wire-cut cookies. $J$ Food Eng 78: 1074-1078.

15. Singh M, Mohamed A. 2007. Influence of gluten-soy protein blends on the quality of reduced carbohydrates cookies. LWT-Food Sci Technol 40: 353-360.

16. Joo NM, Lee SM, Jung HS, Park SH, Song YH, Shin JH, Jung HA. 2008. Optimization of cookie preparation by addition of yam powder. Korean J Food Preserv 15: 49-57.

17. Lee JH, Ko JC. 2009. Physicochemical properties of cookies incorporated with strawberry powder. Food Eng Prog
13: $79-84$.

18. Lee JO, Kim KH, Yook HS. 2009. Quality characteristics of cookies containing various levels of aged garlic. J East Asian Soc Dietary Life 19: 71-77.

19. AACC. 2000. Approved methods of the AACC. 10th ed. American Association of Cereal Chemists, St. Paul, MN, USA. Method 10-52.

20. Seog EJ, Kim HJ, Lee JH. 2008. Color, textural characteristics and sensory quality of strawberry puree-substituted Kochujang during fermentation. J Food Sci Nutr 13: 112116.

21. Lee JH, Han JY. 2009. Physicochemical properties and consumer acceptance of tofu incorporated with Yakong. Food Eng Prog 13: 99-104.

22. Lee JH, Kim JH. 2010. Physicochemical and sensory properties of Baikseolgi incorporated with strawberry powder. Food Eng Prog 14: 271-276.

23. Seog EJ, Kim HR, Lee JH. 2008. Physical characteristics and consumer acceptance of tofu as influenced by water dropwort. J Food Sci Nutr 13: 117-121.

24. Lee JH, Lee HY, Sung CY. 2010. Effect of broccoli powder incorporation on physicochemical properties of cookies. Food Eng Prog 14: 60-64.

25. Lee MH, Oh MS. 2006. Quality characteristics of cookies with brown rice flour. Korean J Food Culture 21: 685-694.

(Received October 25, 2010; Accepted December 9, 2010) 